\title{
Afresco de Fulvio Pennacchi na capela do Hospital das Clínicas da FMUSP: estudos científicos de caracterização material e executiva ${ }^{1}$
}

Regina A. Tirello*

\section{Resumo}

Este trabalho insere-se em projeto de pesquisa voltado a estudos arqueométricos de revestimentos e materiais constitutivos e artísticos de pinturas murais, feitas com a técnica do afresco e executadas em edifícios das décadas de 1940 e 1950 da cidade de São Paulo / Brasil, com ênfase para as obras do pintor Fulvio Pennacchi (18961992). Trata-se de estudo multidisciplinar e interdepartamental que envolve pesquisadores do Centro de Preservação Cultural (CPC) e do Instituto de Geociências (IGc) da Universidade de São Paulo.

Para impostação metodológica dos procedimentos analíticos a adotar futuramente, nesta etapa tomou-se como estudo de caso referencial um dos afrescos realizados por Pennacchi na capela do Instituto Central do Hospital das Clínicas da Faculdade de Medicina da Universidade de São Paulo (FMUSP) em 1946, intitulado "A Anunciação de Nossa Senhora" (2,32m x 2,65m).

Os estudos encadeiam pesquisas histórico-documentais, observações in situ e emprego de instrumental científico de análise para caracterização dos materiais e reconhecimento dos modos de fatura: microscopia petrográfica, microscopia eletrônica de varredura com EDS, difração de raios $X$, microssonda eletrônica e obtenção de imagem por radiação ultravioleta.

Palavras-chave: Conservação e restauração de pinturas murais, Arqueometria, Técnica de afresco.

\section{Fulvio Pennacchi's fresco at the chapel of the Hospital das Clínicas da FMUSP: scientific studies for the characterization of materials and execution}

This paper is part of a research project oriented toward archeometrical studies on characteristic and artistic coats and materials employed in mural paintings, using the fresco technique and applied to buildings in the city of São Paulo, Brazil, dating from the 1940s and 1950s. Special emphasis was given to the works of artist Fulvio Pennacchi (1896-1992). It is a multidisciplinary and interdepartmental study involving 
researchers from the Centro de Preservação Cultural (CPC) and the Instituto de Geociências (IGc) of the Universidade de São Paulo.

To outline the methodology to be used in future analytical procedures, it was chosen as reference case study, one of Pennacchi's frescoes at the chapel of the Instituto Central of the Hospital das Clínicas of the Faculdade de Medicina da Universidade de São Paulo (FMUSP) in 1946. It is called "The Annunciation of Virgin " $(2,32 \mathrm{~m} \mathrm{x}$ $2,65 \mathrm{~m})$.

These studies make use of documentary historical research, in situ observations and use of scientific tools of analysis for materials characterization and for identifying the different ways of making a work of art: petrographic microscopy, scanning electronic microscopy with EDS, X-ray diffraction, electronic microprobe, and the process of obtaining an ultraviolet radiation image.

Key words: Mural painting conservation and restoration. Archeometry. Fresco technique.

\section{Nem toda pintura mural é afresco, nem todo afresco é buon fresco e nem toda têmpera ${ }^{2}$ é de ovo.}

A produção muralística de Fulvio Pennacchi (1896-1992), apesar de profusa e valorizada no Estado de São Paulo, ainda carece de estudos científicos direcionados ao conhecimento objetivo de seus aspectos materiais e executivos, bem como de desdobramentos de pesquisa que interessam diretamente às disciplinas de conservação e restauro de bens culturais.

Pennacchi, ao longo de sua vida, realizou murais em têmpera e a óleo, mas notabilizou-se pelos imensos e excepcionais painéis realizados nas igrejas e residências paulistas que teriam sido feitos com a antiga técnica do "afresco". A expressão fresco - pintura realizada sobre argamassa ainda úmida - invariavelmente nos remete às obras murais renascentistas de mestres como Michelangelo Buonarotti, Piero della Francesca, Raffaelo Sanzio, entre outros e, em conseqüência, à tendência a considerar que esta arte tem um único modo de feitura. 
Entre afrescos quinhentistas e os modernos existem coincidências, é fato, mas, se o objetivo dos estudos for subsidiar tecnicamente iniciativas de conservação e restauração de murais brasileiros, há de se considerar principalmente as possíveis variantes do fazer afrescos. Sabe-se que Pennacchi pintava afrescos. Mas como os pintava?

Como as outras artes, a muralística, ao longo dos séculos, incorporou expressões de diferentes escolas e tendências artísticas que não interferiram apenas na mudança das temáticas e composições, mas reverteram-se principalmente na adoção de novos materiais e modos de execução.

A arte moderna do século $\mathrm{XX}$, ao retomar a antiga arte do buon $f_{\text {resco }}{ }^{3}$, a reinterpretou criativamente, quer no aspecto técnico, quer no estético.

No Brasil, observam-se em pinturas chamadas de afrescos, feitas por pintores como Cândido Portinari, Samson Flexor, Carlos Magano, Marcier, Jenner Augusto, entre os anos de 1940-60, muitos efeitos de texturização rugosa das superfícies pintadas, decorrentes do uso de cargas de diferentes naturezas e granulometrias e mesmo do empastamento de outros materiais com os pigmentos, cuja mistura era aplicada sobre as camadas de massa já secas! Muitos são os exemplos observados com essas características. E sabe-se que não se trata de imperícia e / ou desconhecimento das regras de fatura do buon fresco da escola italiana por parte dos autores, mas de variações executivas intencionais em prol de determinadas resultantes plásticas.

No entanto,

(...) por mais experimental que nos pareça uma obra artística, os materiais que a viabilizam e a constituem não são inertes, nem plasmados de qualquer modo. Existem regras que regulamentam sua estruturação, particulares agregações, dinâmicas internas complexas, determinando diversos tipos. Na maior parte dos casos as variações de trabalhabilidade, resistência, aspecto dos materiais constitutivos impõem-se e se organizam a partir das características intrínsecas das diferentes modalidades de pintura artística ${ }^{4}$.

Nos afrescos modernos persistiram o uso das argamassas de cal e areia e o emprego de uma paleta cromática limitada, composta predominantemente de cores minerais resistentes à causticidade de seu próprio substrato; trata-se de preceitos executivos antigos que garantem bom resultados técnicos e durabilidade às obras. Sem dúvida, a tratadística tecnoartística estrangeira secular sempre significará baliza importante para a impostação de estudos analíticos sobre pinturas modernas, 
mas não deve ser tomada como referência absoluta, o mesmo servindo para as orientações técnicas de restauro.

Nesse sentido, ao estabelecermos os parâmetros metodológicos para o início da colaboração firmada entre o Centro de Patrimônio Cultural (CPC) e o Instituto de Geociências (IGc) da USP ${ }^{5}$ para estudos arqueométricos de revestimentos e materiais constitutivos e artísticos de pinturas murais - que têm como estudos de casos principais obras parietais de Fulvio Pennacchi -, baseamo-nos nas premissas supracitadas. Não nos pareceu suficiente distinguir uma pintura mural somente pelas suas categorias gerais de classificação convencional - buon fresco, mezzo fresco, têmpera a seco, têmpera oleosa -, sob o risco de excessivo reducionismo que pode conduzir, no mínimo, a diagnósticos equivocados das patogêneses que os afetam, sem rebatimentos positivos para futuras iniciativas de conservação e / ou restauro.

Assim, no estudo do primeiro mural da Capela do Instituto Central do Hospital das Clínicas da Faculdade de Medicina da Universidade de São Paulo, intitulado "A Anunciação da Virgem" e realizado por Fulvio Pennacchi em 1946, cujos resultados parciais apresentamos neste artigo, visamos antes de tudo ao aperfeiçoamento de métodos de caracterização de materiais artísticos, buscando fornecer novos dados para profissionais da área da preservação de bens culturais brasileiros e o aperfeiçoamento de nossas práticas.

\section{Sobre a técnica do buon fresco e as suas variantes.}

Pintura em afresco é a pintura executada com pigmentos destemperados com água pura sobre uma argamassa ainda úmida. O processo do afresco usufrui da propriedade da cal de formar - com a areia, a água e as cores - uma estrutura cristalina, resistente e impermeável após a secagem, qualidades distintivas chamado buon fresco.

Para que esse processo se efetive deve existir hidróxido de cálcio (cal extinta) na composição da argamassa. Assim, quando a água contida na massa começa a evaporar, um véu esbranquiçado de carbonato de cálcio forma-se na superfície, indicando o princípio da carbonatação ${ }^{6}$.

Quando essa "secagem-carbonatação" inicia-se, grosso modo, as cores não poderiam mais ser aplicadas, rezam os manuais ${ }^{7}$ tecnoartísticos antigos, pois os pigmentos permaneceriam na superfície da massa, sem a agregação ideal, produzindo dessa maneira pintura potencialmente frágil e solubilizável. 
Também no que toca à execução dos estratos preparatórios, desde a Antiguidade existem regras precisas a serem seguidas: ao emboço regularizador da parede seguem-se dois outros estratos de massa menos espessa e de granulometria mais fina que correspondem às camadas de reboco. Sobre esses estratos de reboco já seco deve ser estendida uma camada de massa finíssima a ser colorida quando ainda úmida. Essa última massa é aplicada em jornadas ${ }^{8}$ para garantir, entre outras coisas, que as superfícies pintadas de uma mesma tonalidade não fiquem manchadas em razão dos tempos de carbonatação diferenciados das massas.

Trata-se de técnica de lenta e difícil execução que, por praticidade e/ou exigência dos tempos, foi gradativamente se modificando. A partir do século XV popularizam-se os murais realizados a mezzo fresco, técnica que acreditamos mais próxima dos afrescos modernos brasileiros.

A principal diferença entre afresco e mezzo fresco está no modo de execução e diz respeito ao grau de carbonatação das argamassas que compõem o substrato da pintura. No mezzo fresco trabalha-se com as cores sobre massas já em adiantado estado de carbonatação, sendo comum aplicar sobre as argamassas quase secas pigmentos destemperados em leite de cal, método esse considerado por alguns pintura feita à têmpera de cal.

Para Guido Botticceli ${ }^{9}$, na técnica do afresco tradicional (o buon fresco), a cal funciona como suporte e, quando carbonatada, também como ligante. Na técnica do mezzo fresco, a cal se constitui no medium e ligante da cor, mas não tem o papel de suporte.

No mezzo fresco, o hidrato de cálcio, uma vez carbonatado e aplicado ao reboco já seco, fixa-se a ele por adesão, ou seja, forma um estrato, uma película. Quando sobreposto à massa (e não integrado à sua estrutura cristalina), o "estrato" de carbonatação que se obtém com esse processo tem resultantes mecânicas, cromáticas e texturais muito diversas daquelas do afresco tradicional, no qual o pigmento foi completamente englobado na argamassa.

O fazer pinturas a mezzo fresco não diz respeito somente às características de fixação da cor, estendendo-se às muitas variáveis constitutivas e de preparo do suporte. Se no buon fresco a utilização de cargas de grãos finíssimos como o pó de mármore na preparação da última camada de massa (que será colorizada) é uma constante, no segundo caso a aspereza pode ser desejada. 
Para obter maior união entre o estrato de cor, a argamassa subjacente à superfície da massa-suporte não pode ser lisa e levigada como um espelho, mas granulosa e rugosa. Esse efeito é obtido picotando-a como se devesse funcionar como emboço do estrato pictórico. Quanto maior a aspereza, maior a coesão da cor ao suporte ${ }^{10}$.

Em estudos de caracterização material já realizados sobre um afresco moderno brasileiro feito pelo artista Carlos Magano ${ }^{11}$ em 1956, na Faculdade de Educação (FE) da Universidade de São Paulo, comprovou-se que o artista, em certos trechos de seu mural, havia usado gesso empastado com cal e pigmentos visando, provavelmente, à obtenção de áreas mais lisas para ressaltar determinadas formas e figuras em meio a uma superfície trabalhada com muitas outras texturas. Nesse caso, tecnicamente, as zonas do mural mais lisas e compactadas, de cores intensas, correspondiam às áreas da pintura relativamente solubilizáveis, predicado indesejável ao buon fresco italiano. Neste mural predominava o sistema do pigmento aplicado sobre massa fresca, mas para conseguir determinados efeitos plásticos o artista usou tintas de têmpera. A técnica mista era intencional, serviu a Magano para sublinhar certos elementos expressivos da obra. Tais distinções técnicas, feitas ainda na fase de diagnóstico de conservação, foram fundamentais para a definição dos métodos de restauro adotados na posterior recuperação do mural ${ }^{12}$, permitindo o emprego de fixativos e reintegrações adequadas à natureza material de cada trecho, respeitando e mantendo suas características materiais originais.

\section{O afresco e Fulvio Pennacchi.}

Fulvio Pennacchi (1905 -1992), pintor de origem italiana, fixa-se em São Paulo na década de 1930. Nesses anos integra o Grupo Santa Helena, com Rebolo, Aldo Bonadei, Alfredo Volpi e Clovis Graciano, entre outros, grupo no qual teve papel destacado. A técnica de pintura em afresco não fez parte de sua formação, vindo a desenvolvê-la de maneira própria após algumas experiências.

Sobre os materiais que utilizava em suas pinturas a fresco, as referências são poucas e vagas. Pietro Maria Bardi, um estudioso da obra desse artista, relata:

Pennacchi não contava com os materiais indispensáveis, mas, depois de provas e mais provas, conseguiu resultados satisfatórios (...). Serviu-se de cal viva dissolvida em água, conservando-a, depois de bem descansada e bem colada, em recipiente fechado. Isso era a base de um bom resultado. Conta o pintor:'Para surpresa, tive na experiência ótimos resultados, como se tivesse nascido conhecendo muitos segredos ${ }^{\prime 13}$. 
Nada é dito a respeito dos procedimentos executivos.

Depreende-se do texto que certos preceitos do buon fresco, como o uso de argamassas de cal, integram os fazeres de Pennacchi; confirmam-se também as experimentações em torno da técnica, mas esse tipo de informação pouco esclarece sobre os componentes materiais que viabilizaram os particularíssimos resultados plásticos que se observam na obra mural desse pintor.

O que se vê em seus afrescos são grandes áreas de superfícies com os grãos grossos de areia brilhante expostos, que se alternam com outras formas definidas por massas compactadas (destacadas ou não por pinceladas finas e suaves), entre outras variantes texturais cujos resultados finais são extraordinários efeitos de relevo.

Pennacchi pinta com técnicas mistas e / ou aqueles resultados decorrem de especial modo de trabalhar / misturar as argamassas do substrato? Essa foi a questão que nos colocamos para estruturar nossos primeiros estudos analíticos e selecionar a instrumentação laboratorial de apoio na direção de uma melhor compreensão da obra desse muralista. Identificar os materiais constitutivos e suas características de mistura, relacionando-os às formas de aplicação artística, é o objetivo maior da primeira etapa desta pesquisa.

Para esse fim foram selecionados dois afrescos: (mural 1) "A Anunciação de Nossa Senhora" (2,32m x 2,65m) e (mural 2) "A Ceia de Emaús" (2,37m x 2,45m), realizados pelo pintor em 1946 na Capela do Instituto Central do Hospital das Clínicas da Faculdade de Medicina da Universidade de São Paulo (FMUSP). Aqui estão sendo apresentados resultados parciais do primeiro painel. Cumpre salientar que, no que tange às condições de conservação geral desses murais, salvo algumas áreas atacadas por microorganismos no mural 2 - em decorrência da adoção de materiais impróprios em restauração realizada no passado -, essas pinturas encontram-se em bom estado, o que permitiu a retirada de material representativo para as análises pretendidas. 


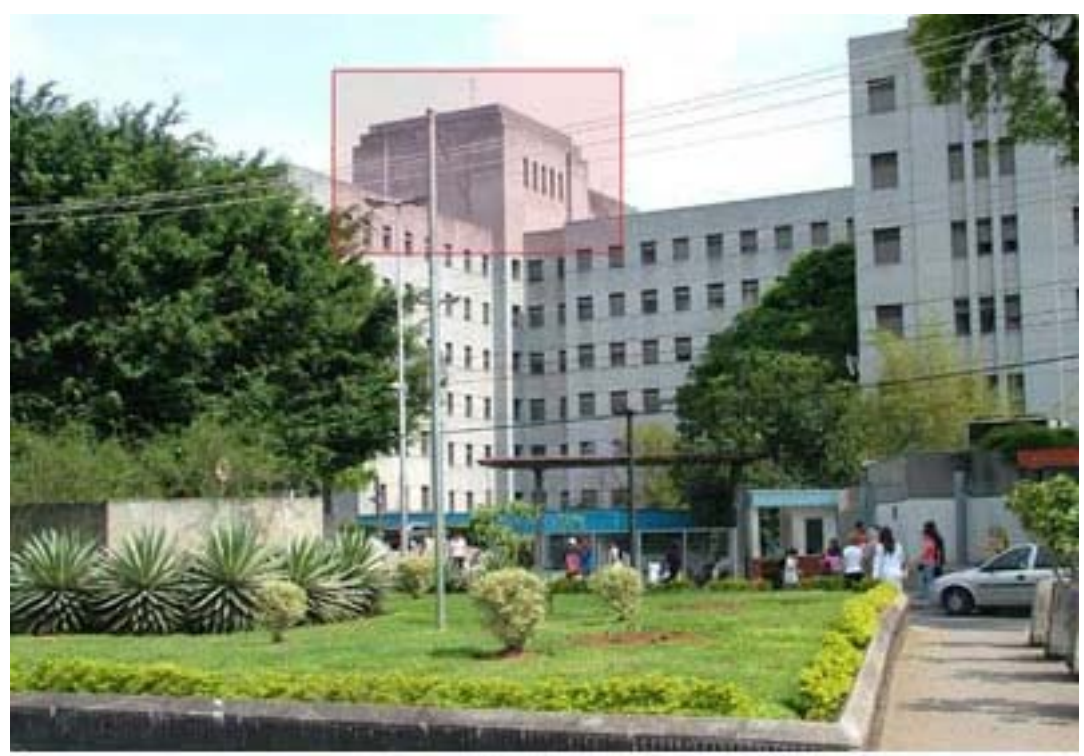

FIGURA 1 - Edificio do Instituto Central do Hospital das Clinicas da Faculdade de Medicina da Universidade de São Paulo. A capela pintada por Fulvio Pennacchi situa-se no $11^{\circ}$ andar do edificio. Foto: Lauro Dehira, 2005.
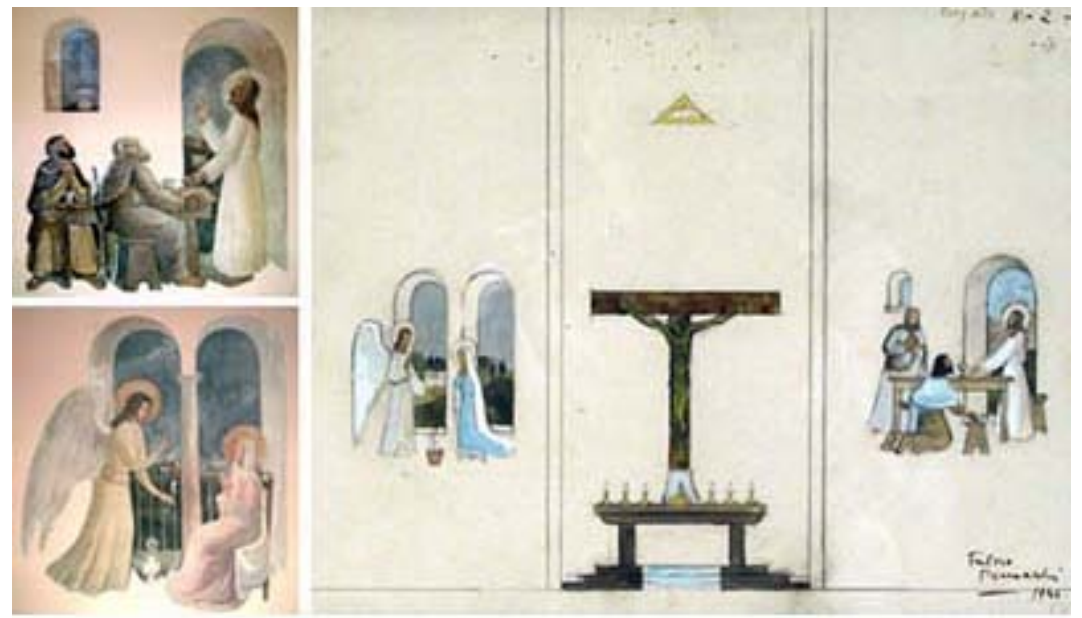

FIGURA 2 - Esboço do projeto proposto por Fulvio Pennacchi, em 1946, para ornamentação da capela do $\mathrm{HC}$ com murais representado a "A anunciação da Virgem" e a "Ceia de Hemmaus". Na execução das obras permaneceram o tema, tonalidades e localização, mas a composição das figuras foi alterada (ver figuras à esquerda do quadro). Fotos: Angela Garcia, 2005 


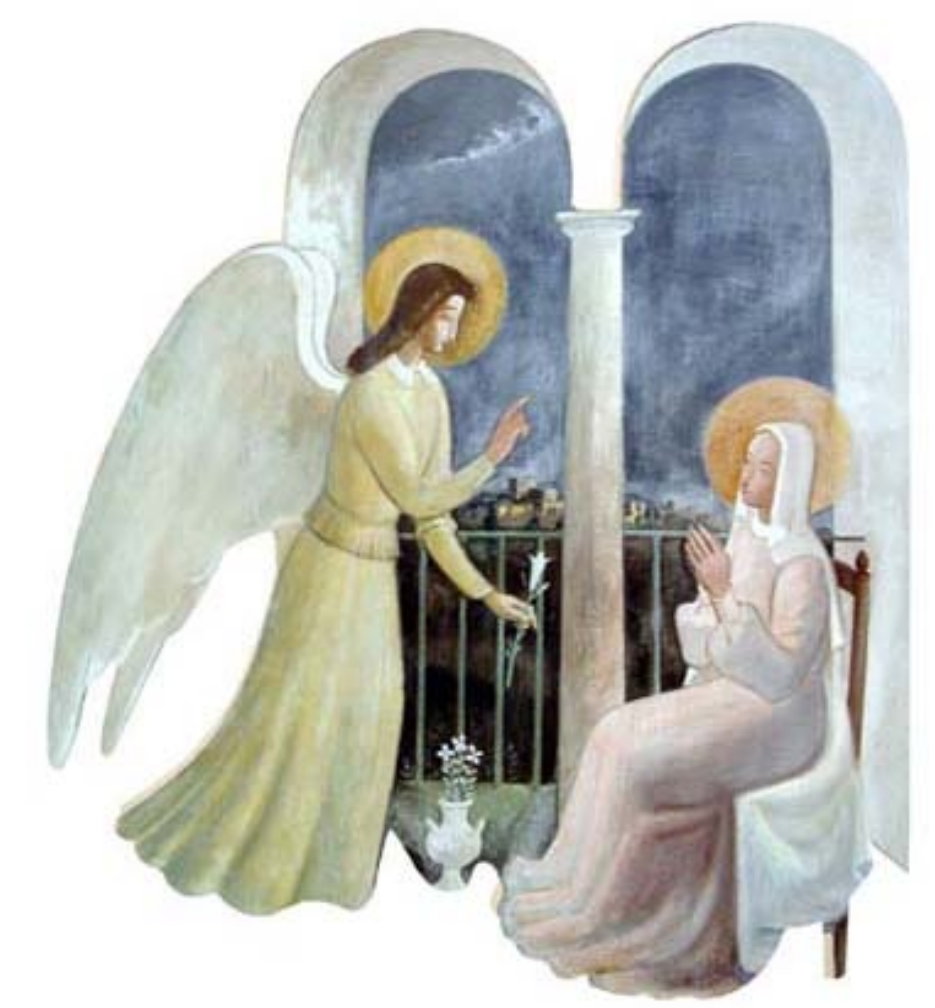

FIGURA 3 - Mural estudado analisado nesta etapa do projeto: "A anunciação da Virgem" $(2,32 m \times 2,65 m)$, painel 1. Foto Ângela Garcia, 2005 .

Análises morfológicas texturais de afrescos de Fulvio Pennacchi: metodologia.

A exposição completa das fases de estudos que precederam os exames de caracterização, com seus objetivos e resultados intermediários, seria muito extensa. Aqui, serão descritas a seguir as etapas principais e as hipóteses geradas a partir das observações in situ, que indicaram a categoria dos exames de caracterização a serem realizados.

1' Etapa: Reconhecimento do objeto. Nesta etapa foram realizados: pesquisa histórica, estudos de tratados e manuais tecnoartísticos, levantamentos métricos, registros fotográficos preliminares e análises empíricas de campo.

2a Etapa: Investigação da técnica. Esta etapa foi subdividida conforme itens a seguir: 
- Estado de conservação: avaliação da superfície, estabilidade do suporte e pigmentos observando-se alterações antrópicas (restauros anteriores) e naturais (eflorescências, desbotamento, pulverulência etc.);

- Estudos formais: observação da morfologia da superfície (texturização da argamassa, marcas de jornadas e incisões); (FIGURA 6)

- Características autorais: modo de aplicação de materiais pictóricos e argamassas e paleta cromática.

Usou-se para esta etapa a seguinte instrumentação de apoio: documentação fotográfica com luz visível (detalhamento técnico), luz rasante (morfologia/texturização) e radiação ultravioleta (identificação de alterações e/ou emprego de materiais estranhos à técnica original e imperceptíveis a olho nu), gerando desenhos e mapas-sínteses das questões observadas (FIGURA 4,5,7 e 10)

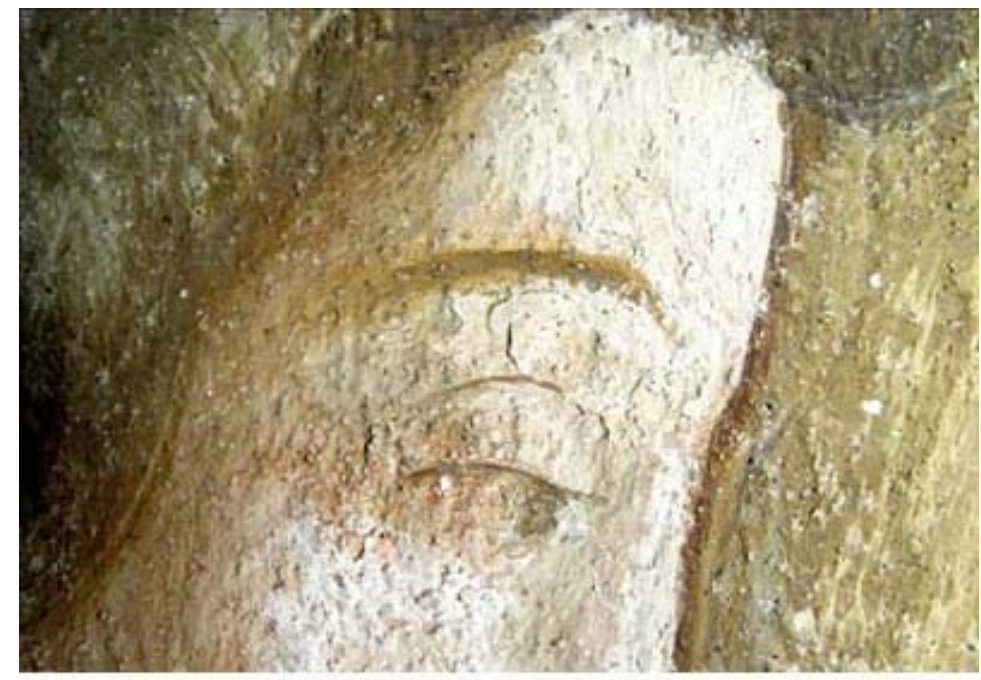

FIGURA 4 - Exemplo de "textura tipo 2" na face do anjo do painel 1. Caracteriza-se pela aplicação de material colorido espesso que encobre completamente a texturizaçāo do reboco subjacente. Foto Ångela Garcia, 2005. 


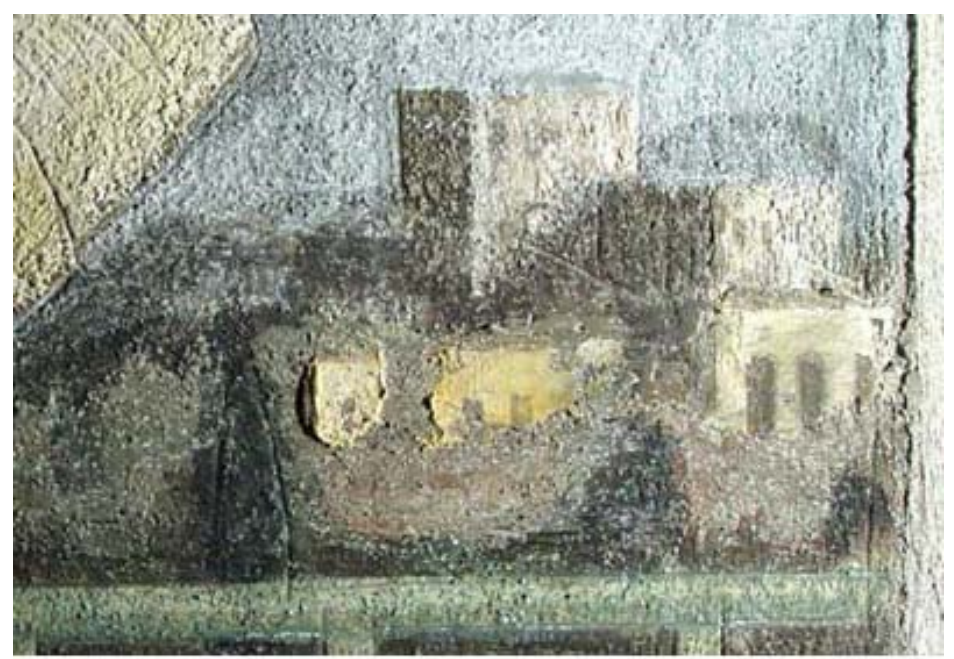

FIGURA 5 - Trecho do painel 1 representando arquiteturas que exemplifica as muitas variantes texturais adotadas por esse pintor. Foto Ångela Garcia, 2005.

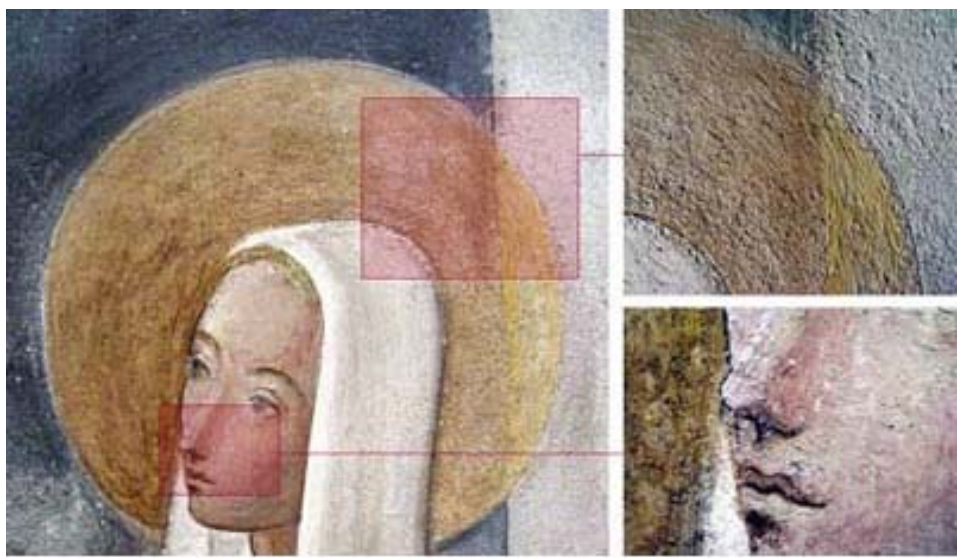

FIGURA 6 - Tipos de texturização variadas em um mesmo trecho do painel 1. Foto: Ângela Garcia, 2005.

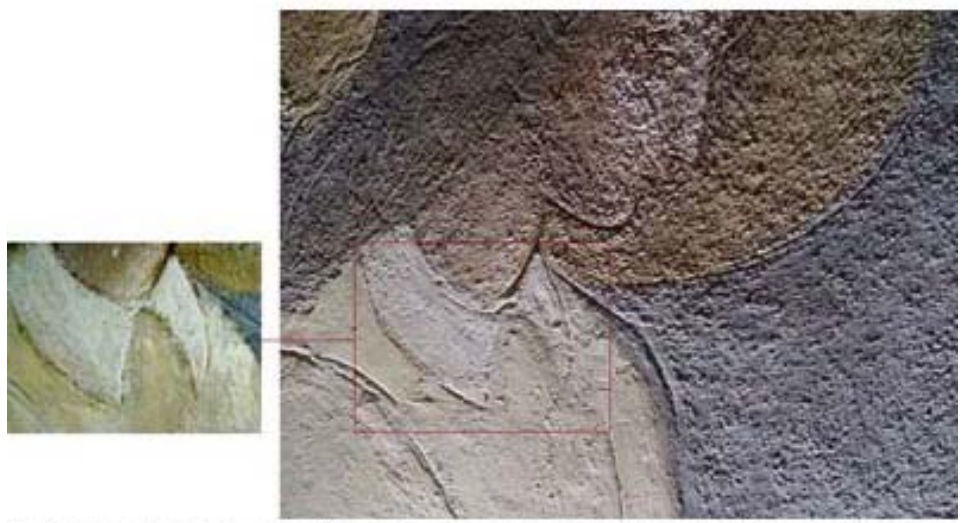

FIGURA 7 - Imagem realizada com luz rasante para estudo morfológico da pintura. A área corresponde a "textura tipo 3 ". Observar superficie lisa de parte das vestes da figura. Foto Ảngela Garcia, 2005. 
3 Etapa: Geração de hipóteses. A partir do estudo distintivo da morfologia textural e do reconhecimento das áreas comprovadamente originais gerou-se mapeamento com indicação dos pontos relevantes para extração de amostra material para exames de caracterização a serem realizados no IGc-USP pela professora doutora Eliane A. Del Lama.

As principais hipóteses levantadas até esta fase da pesquisa foram:

Hipótese A: Para regularização do suporte, Pennacchi usou uma única argamassa para execução de reboco tradicional. As diferentes texturas observáveis na obra viabilizam-se pela adição de outros materiais à argamassa.

Hipótese B: Para obter áreas coloridas de textura lisa, os pigmentos aparentemente são aplicados como "tinta" (pigmento + medium) sobre a argamassa do substrato. É uma pintura a têmpera.

4- Etapa: Análise dos materiais constitutivos da obra. Esta etapa constituiu-se de retirada de microamostras para: reconhecimento da composição, identificação dos componentes da argamassa e obtenção de informações a respeito da granulação, impurezas, minerais presentes e características texturais dos minerais. (FIGURA 11)

Para averiguar as hipóteses geradas, elegeram-se as seguintes técnicas analíticas: microscopia petrográfica, microscopia eletrônica de varredura com EDS, difração de raios $\mathrm{X}$ e microssonda eletrônica.

\section{Primeiros resultados ${ }^{14}$}

No mural "A Anunciação da Virgem", identificaram-se três grandes grupos de texturas, abaixo discriminadas. (FIGURA 8)

- Textura tipo 1: Corresponde a trechos de massa pigmentada, de aspecto bastante granuloso, com agregados visíveis. A cor espalha-se nos interstícios dos grãos, sem formar camada aparente, como se aplicada quando a massa estivesse úmida. Sugere processo completo de carbonatação.

- Textura tipo 2: Material colorido espesso que distribui-se nos trechos grandes e mais abstratos da composição, encobrindo completamente a texturização da argamassa de reboco subjacente. (FIGURA 9)

- Textura tipo 3: Superfícies lisas, com aplicação de "massa e/ou tinta" homogênea, formando camadas de textura fina, levigadas. Sobre superfícies com essas 
características pode ter ou não riscos feitos a pincel, em tons terra, definidores das formas representadas
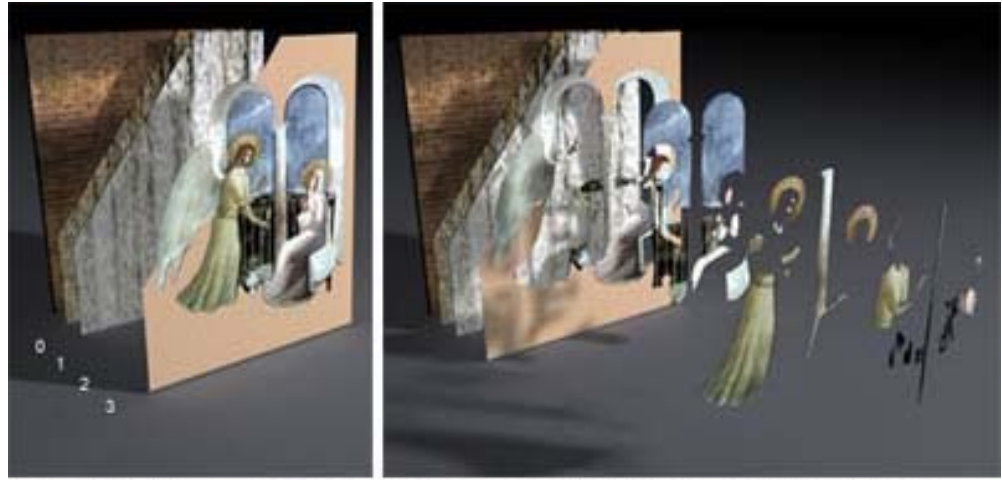

FIGURA 8 - No primeiro quadro, representação do sistema preparatónio adotado: suporte de tijolos ( 0 ) emboço (1), reboco (2) e último estrato de massa fresca colorizada (3). No segundo quadro, representação tridimensional dos 3 grandes grupos de textura estudados nesta etapa da pesquisa. Desenho: Pedro Murilo, 2005.
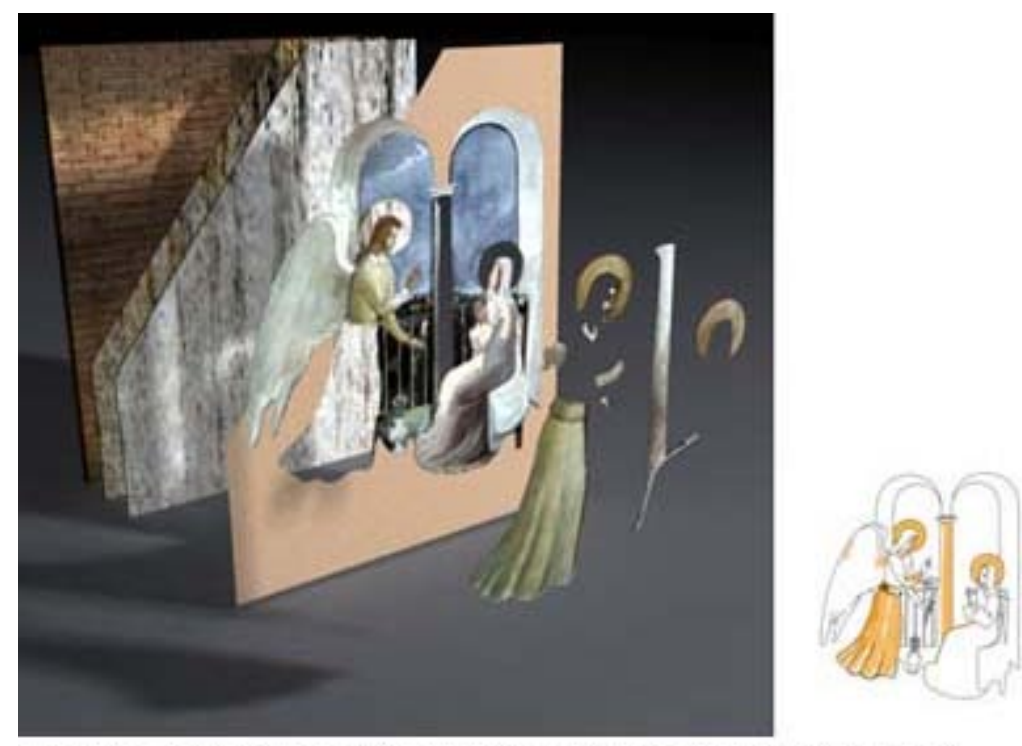

FIGURA 9 - Representação tridimensional e gráfico das áreas de "textura n.2". Desenho: Pedro Murilo, 2005. 


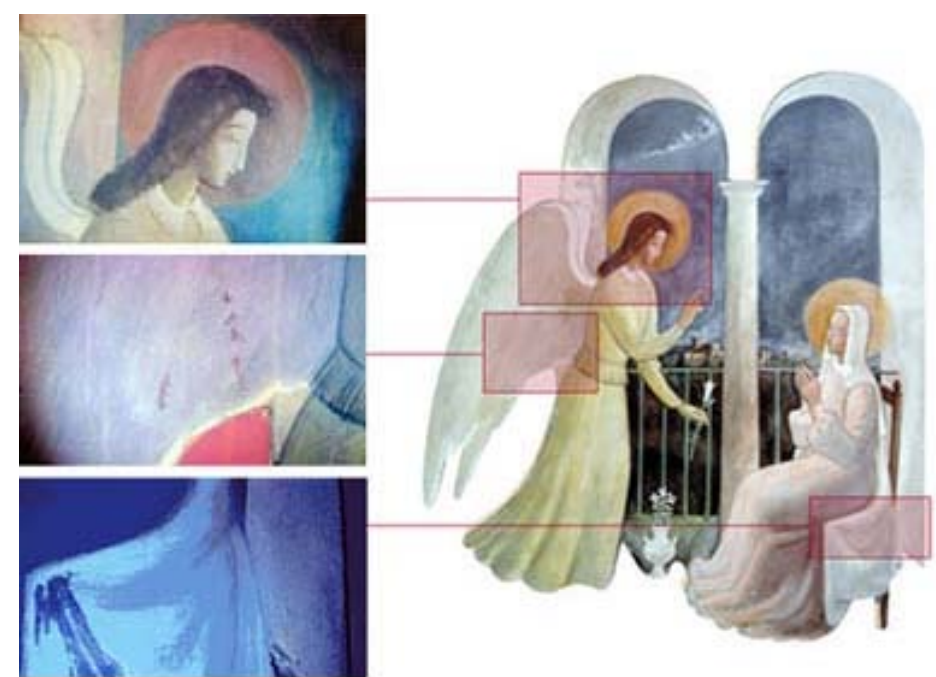

FIGURA 10 - Emprego de radiação ultravioleta (UV) para distinção das áreas originais daquelas repintadas em restauro realizado nos anos de 1970 sobre o qual não existe documentação. O procedimento possibilita a seleção adequada das zonas passiveis da extração de micro-amostras para exames de caracterizaçāo. Foto Ångela Garcla, 2005.

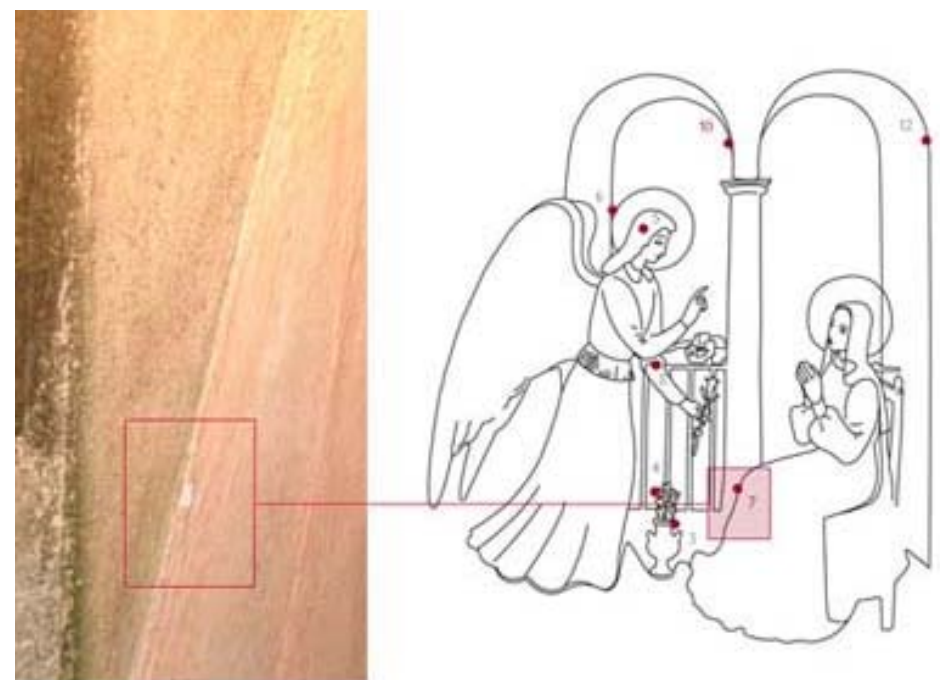

FIGURA 11 - Mapeamento dos pontos de onde foram retiradas as micro-amostras para análise dos materiais constitutivos, definidores das caracteristicas executivas e texturais da obra. Foto Ångela Garcia, 2005.

\section{Conclusões sobre a Hipótese A:}

Pennacchi usava como reboco uma argamassa geral com aglomerante e agregados finos e médios. Análises preliminares apontam que o principal constituinte da massa é a cal cálcica, com presença constante de calcita.

É muito provável que o pintor não usasse cal calcítica pura, pois foi detectada a presença de magnesita, gipsita e epsomita. Esses minerais podem indicar que ele tenha usado cal impura ou gesso, ou que esses minerais sejam oriundos da 
dissolução e da alteração do cimento presente de revestimento geral da parede que confina com a área afrescada. Análises do material do revestimento externo do edifício (massa fulget) e das massas de rejunte do muro-suporte complementarão / esclarecerão esses resultados.

Com o aprofundamento dos exames dos sistemas de argamassas (exteriorinterior), tenciona-se esclarecer se os minerais "estranhos" à técnica clássica do buon fresco identificados até agora são oriundos dos materiais constituintes do muro e / ou se são característicos das massas de emboço / reboco usadas por Pennacchi.

Os agregados dessas massas são constituídos majoritariamente por quartzo, aparecendo também muscovita e traços de feldspato e turmalina.

Das imagens obtidas no Microscópio Eletrônico de Varredura (MEV) deduz-se que a amostra coletada no trecho da textura tipo 1 apresentam agregados, sem formação de camada, do que se deduz também que, em áreas correspondentes a essa categoria de texturização, os pigmentos estão perfeitamente englobados no reboco final da obra (TIRELLO e DEL LAMA, inédito) ${ }^{15}$.

\section{Sobre a Hipótese B:}

Já as imagens obtidas relativas à amostra recolhida em área de textura tipo 2 , vão ao encontro das questões levantadas a respeito do uso de "temperas" diferenciadas em muito trechos da composição, reforçando a necessidade de se empreender mais estudos nesta direção. Nas micrografias apresentadas na imagem 12 deste texto observa-se a existência de duas finas camadas, 1 e 2 (com composição química semelhante), com nítida interface, sugerindo que a aplicação da camada 2 ocorreu após secagem completa da camada 1. Nota-se ainda um finíssimo estrato de cal, sem agregados, que pode corresponder a um particular modo de aplicação da cor. (FIGURA 12)

Os resultados dessas primeiras análises de caracterização da morfologia textural dos afrescos de Pennacchi, das quais aqui apresentamos apenas uma imagem, serão cotejados com outras obras do pintor no âmbito do projeto de pesquisa em desenvolvimento.

Aqui, a intenção foi apresentar os primeiros resultados das analises formais $e$ materiais até agora empreendidas pelo CPC e IGc com o que se espera estabelecer contatos com outros pesquisadores da área da conservação de pinturas murais e interessados na em estudos da obra de Fulvio Pennacchi. 
Como já assinalado no início, o objetivo deste trabalho de colaboração interdisciplinar é a realização e divulgação de estudos fundamentais buscando o aperfeiçoamento das práticas de restauro brasileiras (TIRELLO e DEL LAMA, inédito) ${ }^{16}$.

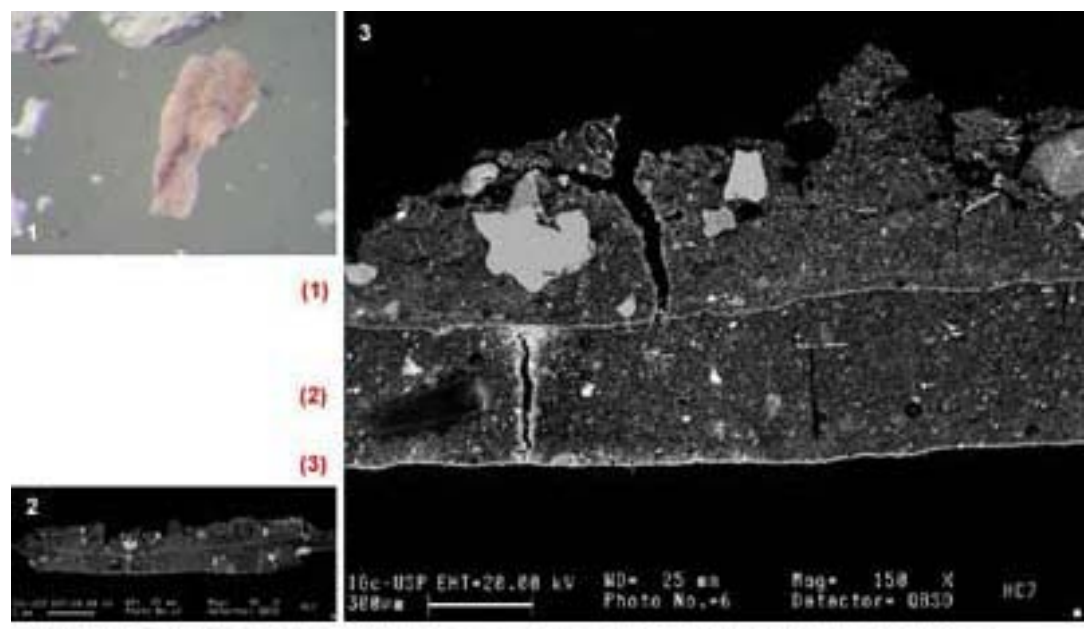

FIGURA 12 - No quadro, imagens relativas ao estudo morfológico e elementar da amostra n. 7, a: (1) área de que foi recolhida (2) amostra observada de "topo" no microscópio binocular. (3) Micrografia 1: back scatted. Microfotografia: Eliane Del Lama, 2005. Micrografia: Isac Jamil Saied, 2005.

\section{Notas}

1 Uma outra versão do trabalho aqui apresentado, intitulada Fresco Brasileño Moderno: Estudios de caracterización material y ejecutiva de los murales de Fulvio Pennacchi, foi apresentada no I Congreso Argentino de Arqueometria: Metodologias científicas aplicadas al estúdio de los bienes culturales: datacíon, caracterizacíon, prospeccíon, conservacion (Rosário, Argentina, 2005) pela autora (CPC-USP) e pela Profa. Dra. Eliane A Del Lama, do Instituto de Geociências (IGc) USP, responsável pelo projeto Fapesp n5/51310-3, do qual este trabalho é um dos primeiros produtos.

${ }^{2}$ Têmpera: Na antiguidade o termo era usado para designar pigmentos misturados com água e empatados com materiais orgânicos (colas, ovo, gomas). Já Giorgio Vasari adotava a expressão para referir-se a todo tipo de tinta, fosse essa a base de água ou de óleo. Hoje, entende-se como pintura a base de emulsão diluída em água misturada a pigmentos empastados também com água. Esta emulsões podem ser naturais (leite, ovo, amidos e etc) ou artificiais (cal, caseína, cola e etc). Caracteriza-se, portanto por tinta (pigmento + medium) a base de água.

${ }^{3}$ Ver tópico específico sobre o assunto neste trabalho.

${ }^{4}$ TIRELLO, Regina A. (org.). O restauro de um mural moderno na USP: o afresco de Carlos Magano; CPCPRCEU-USP. 2001, p.64. 
${ }^{5}$ O projeto de pesquisa "A Mineralogia Aplicada ao Estudo de Pinturas Murais: Fulvio Pennacchi - um estudo de caso“ (Fapesp n.05/51310-3) coordenado pela Profa. Dra. Eliane Del Lama, do IGc-USP, com o qual estamos tendo o privilégio de colaborar, representa grande passo na direção da normatizaçao de estudos e procedimentos na área da conservação de murais modernos e antigos brasileiros. Consolida e aprofunda efetivamente as colaborações entre cientistas e conservadores de bens culturais que, na Universidade de São Paulo, vem ocorrendo desde do inicio da década de 1990 de forma pulverizada. A médio prazo, o objetivo do projeto é estruturar um laboratório de pesquisa aplicada como suporte aos trabalhos de preservação.

${ }^{6}$ É quando o hidrato de cálcio combinando-se com o anidro carbônico presente no ar transforma-se em carbonato de cálcio.

7 Um manual caracteriza-se por não ser um livro teórico. Nele registram-se instrumentos e técnicas, características gestuais e tempo médio para execução das operações necessárias às praticas de que trata. É sempre a tentativa da transcrição de um saper fare por meio de regras compreensíveis e minimamente reprodutíveis.

${ }^{8}$ Jornada: sobre o desenho preparatório realizado sobre o reboco seco, a massa fresca é aplicada em trechos, de perímetro não muito grande, feitos dia a dia.

${ }^{9}$ BOTTICCELI, G. Técnica e Restauro delle Pitture Murali. Milano: Edizione Polistampa,1980, p.20.

10 MATTEINI M.; MOLES A.; MANGANELLI Del Fà G. Stato di Conservazione della Giudita e Oloferne. In: Metodo e scienza - operatività e ricerca nel restauro. Firenze: Sansoni, 1982, p.164-5.

${ }^{11}$ Carlos Magano (1921-2005) Sobre o artista ver CAMPOS, Maria Cristina André. Carlos Magano e a pintura mural. In: TIRELLO, Regina A. (org.). O restauro de um mural moderno na USP: o afresco de Carlos Magano. CPC-PRCEU-USP. 2001, p.43-55.

12 O mural de Carlos Magano, intitulado "A Marcha do Conhecimento Humano" (14,70m(c) x 4,27m(h)), realizado em 1956 ,no Bloco B da Faculdade de Educação da USP, no campus de São Paulo, foi estudado e restaurado no âmbito do programa de formação prática de restauro de pinturas murais, então intitulado "Canteiro Escola de Restauração" do CPC. Deste trabalho resultou livro de características didática, constante na bibliografia deste texto .

${ }^{13}$ BARDI, Pietro Maria. Pennacchi. São Paulo: Raízes Artes Gráficas Ltda,1980, p.24.

14 Participantes do estudo do mural 1 da capela do HC-FMUSP "A anunciação da virgem": Centro de Preservação Cultural da USP: Regina Andrade Tirello: Coordenação da pesquisa de campo / estudos formais e diagnósticos; Estagiários: Camila Marcatti, Pedro Piccino Alasmar, Pedro Murilo G. Freitas; Fotografias: Angela Garcia. Instituto de Geociências (IGc) da USP: (Fundação de Amparo à Pesquisa do Estado de São Paulo FAPESP: Proc. n.05/51310-3) Eliane Aparecida Del Lama: Coordenação das análises laboratoriais; Microscopia eletrônica: Isaac Jamil Saied (IGc-USP). 
15 Trabalho inédito submetido ao comitê científico do I Congresso Argentino de Arqueometria: Metodologias científicas aplicadas al estudio de los bienes culturales: datacion caracterizacion, prospeccion, conservacion Rosário, Argentina, 2005. As análises de microscopia eletrônica coordenadas pela professora doutora Eliane A. Del Lama integram o trabalho "Fresco brasileño moderno: estúdios de caracterización material y ejecutiva de los murales de Fulvio Pennacchi”.

16 Trabalho inédito submetido ao comitê científico do I Congresso Argentino de Arqueometria: Metodologias científicas aplicadas al estudio de los bienes culturales: datacion caracterizacion, prospeccion, conservacion Rosário, Argentina, 2005. As análises de microscopia eletrônica coordenadas pela professora doutora Eliane A. Del Lama integram o trabalho "Fresco brasileño moderno: estúdios de caracterización material y ejecutiva de los murales de Fulvio Pennacchi”.

\section{Referências bibliográficas}

BARDI, Pietro Maria. Pennacchi. São Paulo: Raízes Artes Gráficas Ltda,1980.

BOTTICCELI, G. Técnica e Restauro delle Pitture Murali. Milano: Edizione Polistampa, 1980.

BRUNI, S., GAGLIARDI, M., MAIONO, G., BIAGI MAINO, D. Investigation of XV Century frescoes by means of electron microscopy and microanalysis. In: Symposium on Archaeometry. Atenas: Helenic Society for Archaeometry, 2003, p.4.

BUZZEGOLI E., KUNZELMAN D., BERTANI D., CETICA M., POGGI P., Methods and Results of Non-Invasive Testing: Infrared Reflectography and False Color, Heures de Turin-Milan. In: Commentary, Museo Civico di Torino e Faksimile Verlag Luzern 1996, p.395-401.

GARCIA, A. Fotografia Ultravioleta: o registro das imagens espectrais. In: TIRELLO, R.A. (org.). O restauro de um mural moderno na USP: o afresco de Carlos Magano. São Paulo: CPC-PRCEU-USP, 2001, p.150-153.

LOURENÇO, M.C.F. (org.). Bens imóveis tombados ou em processo de tombamento da USP. São Paulo: Edusp, Imprensa Oficial do Estado de São Paulo, 1999.

MATTEINI M; MOLES A; MANGANELLI Del Fà G. Stato di Conservazione della Giudita e Oloferne. In: Metodo e scienza - operatività e ricerca nel restauro. Firenze: Sansoni, 1982.

TIRELLO, Regina A. (org.): O restauro de um mural moderno na USP: o afresco de Carlos Magano; CPCPRCEU-USP, 2001.

* Arquiteta. Doutora pela FAU-USP. Especialista em conservação e restauro do Centro de Preservação Cultural da USP e docente do Departamento de Arquitetura e Construção da Faculdade de Engenharia Civil da Unicamp. 